\title{
Circular Insurance: customer-centric, data-driven services for the Circular Economy
}

\author{
Phil Godsiff \\ University of Exeter Business School \\ P.J.Godsiff@exeter.ac.uk
}

\begin{abstract}
Advances in digital technology are driving the digital transformation of many sectors facilitating new business models, changes to business processes and the emergence of technology-driven start-ups. It is clear that technology is important in facilitating a servitisation business model. However, customers are increasingly identified as the ones driving innovation and, therefore, the digital transformation of an organisation. There is also a push for all sectors to play their role in moving to a more sustainable system by embedding Circular Economy principles into their organisations. This conceptual paper explores the interactions between digital transformation, servitisation and the Circular Economy and how these might transform the insurance sector, leading to the proposal of a new finance insurance ecosystem, Circular Insurance. The implications for the future of the insurance market are explored highlighting areas of future research and the beginnings of a possible research agenda.
\end{abstract}

\section{Introduction}

There is much excitement around the potential of digital technologies to enhance the efficiency of organisations. Being able to leverage the power of digital technology is particularly important at present, where a global pandemic is forcing us to reconsider the ways in which we work, how an organisation might interact with their customers and what services are offered to customers.

Digital transformation involves an organisation innovating their organisational strategy based on the adoption of new technology [1]. Much of the transformation is data-driven. All components of the organisation will be effected by the transformation process including their operating model, business model, digital strategy and their relationship with their customers.

\author{
Zena Wood \\ University of Exeter Business School \\ Z.M.Wood2@exeter.ac.uk
}

With current linear models (i.e., the take-make-waste extractive industrial product based model) considered to be reaching their physical limits [2], the Circular Economy aims to move towards a more sustainable system by focusing on three principles: design waste out of the system, keep products and materials in use, and regenerate natural systems [3]. It is important that all sectors play their role in moving to 'restorative and regenerative' systems by embedding CE principles in their organisations [2].

The UK insurance sector is the largest in Europe contributing $£ 29.1$ billion to the UK economy in 2017 and employing over 300,000 people [4]. Traditionally insurance is mostly about understanding risk. A customer will request a quote for a policy that would insure them against loss usually through monetary compensation. The insurance company would use data provided by the company, in addition to their own probabilities and statistics, to assess the customer's risk profile and calculate the cost of the insurance premium. This process would repeat when the policy needs to be renewed (typically annually). The price of the existing policy must be acceptable to the customer whilst allowing the insurance company to have sufficient funds to make a profit whilst being able to pay expenses and any future claims. Traditional insurance products mitigate against and create significant financial barriers to the adoption of alternatives to the take-make-waste industrial product based model.

Existing surveys (such as that of Deloitte [5], McKinsey \& Company [6] and PwC [7]), and our own discussions with representatives of the insurance sector, have shown that this traditional model is no longer appropriate. Servitisation allows companies to deliver capability (i.e., an outcome) rather than the traditional product-based offering; companies can maintain their competitive advantage and increase the value that they can offer to their customers [8]. A Deloitte survey (2019) of 200 executives from within the insurance sector [5], highlighted services as a way of engaging customers 'with offerings that add value'. However, if 
they are to thrive against competition from technology based data driven start ups, insurance companies would need to be able to offer services and products that are tailored and relevant to the customer at the time that they need them. The tailoring and relevancy of services are difficult to achieve in an analogue world and are only possible through a data-driven approach. Many organisations are now able to capture vast amounts of data, the analysis of which could provide insights and actions leading to new value propositions.

Some areas of insurance (e.g., parametric insurance) use a data-driven approach. Typically used to insure against natural disasters, parametric insurance makes use of IoT data and data analytics to remove the costs and time of claim processes and loss adjusters. A pay out is made automatically when the natural disaster occurs (i.e., pays out on event not on consequential loss). However, we believe a data-driven, customer-centric approach could go further, utilising data and data analytics to help move towards a model which aims to prevent risk by advising customers on how to prevent risk, and or the likelihood of an event occurring (e.g., flooding event likely soon).

In addition to being data-driven, servitisation business models should be customer-centric. The move from an analogue world to a digital one (i.e., digitisation), has led to the 'age of immediacy' and new demands. Customers are typically the driving force in innovation and determining the offerings of an organisation. Insurance providers need to move through innovative product offerings (e.g., parametric insurance), to more holistic and customer-focused offerings which will involve constantly innovating the business model. This move now appears possible due to datafication, advances in digital technologies and servitisation.

This conceptual paper proposes a customer-centric, data-driven approach to insurance, Circular Insurance, a new finance insurance ecosystem that uses innovative digital technologies to encourage and reward behaviours that embrace and enhance CE principles. Circular Insurance relies on access to data and suitable data analytics methods. The possibility of a data-driven and customer-centric approach brings in to question the benefits and barriers of personal data usage, data sharing and ownership, data-driven business models, the use of an eco-system approach (rather than a sectoral silo), transparency of AI and real-time data collection and analytics.

A review of existing industry surveys are given that explain the state of the market, the need for change and the motivations behind this research (section 2) before exploring each aspect of Circular Insurance and how it encourages and enhances the CE principles (section 3). Section 5 discusses the barriers and challenges to adoption of the new financial ecosystem. The paper concludes with a list of areas of future research that are required for it to become the next stage in insurance (section 6).

\section{Motivations}

Discussions with practitioners from within the insurance sector have highlighted a changing competitive landscape, the impact of technology and a possible evolution of the supply chain. Opportunities for change in operating models, business models and relationship with the customer have also been identified [9]. The UK has the world's fourth largest insurance market [10]. Digitalisation can remove geographic boundaries and open up global opportunities. However, the challenges that potential global markets bring, and the acceleration of digital transformation, means that the UK insurance sector must adapt in order to remain competitive. Automation had already been seen as a disruptive force within insurance [6,7]. The recent pandemic has forced investment in technology to facilitate continued service delivery through remote working. Technology that was previously considered inappropriate has now been considered or even embraced.

The results of our discussions are compounded by recent sector surveys that industry groups have undertaken to identify future trends and how organisations within the sector will need to adapt to survive and thrive within the Digital Economy. These surveys and our own discussions with representatives of the insurance sector as part of ongoing research, have shown that the traditional model is no longer appropriate.

Deloitte surveyed 200 executives from within the insurance sector, specifically Property and Casualty (75 respondents), Life Insurance and Annuity (75 respondents) and Reinsurance/Global Speciality (50 respondents) [5]. The survey identified four key trends that were necessary for an insurance company to thrive in 2020: the changing needs of the customer, identifying new options for growth, being able to utilise new technologies to their advantage and the need for partnerships to ensure growth. The report notes that customers were considered to be the 'disruptive force in the industry' [5] and questioned how insurance might adapt to customer demands. The needs and expectations of the customer were considered to be the top challenge by $45 \%$ of the survey respondents.

The report noted that insurance companies would 
need to go beyond their traditional core offerings if they were to maintain their customer base. $63 \%$ of the insurers that responded to the survey believed that non-insurance products would be a key factor that a customer would consider when choosing an insurer. The survey also noted that the growth of an insurance company would come from 'new service-based models, innovative products and a greater focus on prevention'. 95\% of respondents believed that, over the next three years, the use of advanced analytics would increase. The report also noted the need for an ecosystem.

McKinsey \& Company produced a report aimed at helping executives within the insurance sector understand and capture value in a digital world [6]. Although there has been reluctance to change existing business and operating models in the sector, the need for incumbents to change is emphasised with those that act early likely to be the ones that thrive: 'Insurers have a choice: be disrupted or be the disruptor with new products, services, and business models' [6]. The report recognises the importance of the customer, their changing expectations, and their desire for tailored services, driven by digital technology. The authors note that improvements in services through digitisation, will lead to increased customer retention.

Data analysis opportunities will allow insurance companies to have a better understanding of their customers facilitating more personalised products and services (e.g., offering car insurance by the mile, offering services related to moving home when data shows a customer has put their house on the market). Innovative products and protection services are given as the areas where future growth will occur; cyber-security products are listed as one such example that will be more prevalent in a digital world. McKinsey identify the move towards risk prevention, and the power of companies that own and analyze the required data, as two trends that threaten the insurance sector as it currently stands.

\section{Circular Insurance}

As researchers, we find ourselves at the confluence of three themes: digital transformation, servitisation and the Circular Economy(CE). These have many common elements but all ultimately imply changes to impact existing business models and are driven by data. Based on our ongoing research in servitisation, $\mathrm{CE}$ and the insurance sector, we have developed the concept of Circular Insurance, a new finance insurance ecosystem that uses innovative digital technologies to encourage and reward behaviours that embrace and enhance $\mathrm{CE}$ principles. This section will explore each of these features. Section 4 presents a possible solution design for the ecosystem that includes the use of Personal Data Stores (PDSs) and a risk management framework.

\subsection{Embracing digital transformation}

Circular Insurance is built on the need for digital transformation, which can be defined as digitisation, datafication and digitalisation [11]. Digitisation (i.e., the conversion of analogue to digital) drives digitalisation, which occurs when there is an innovation in an organisation's business model. Datafication, the collection and analysis of this data, is only possible through digitisation. Many organisations are now able to capture vast amounts of data, the analysis of which could provide insights and actions leading to new value propositions [9]. Datafication is a key component of digital transformation and can be considered a 'sense making process' [12].

Digitalisation can lead to challenges and opportunities within the insurance sector [9]. Digitalisation and datafication will allow innovation in the firm's business model [11] in which the entirety of the business has to adopt a digitally and customer focused mindset. For insurance, this innovation in business model will focus on a servitisation business model that focuses on the prevention of risk instead of the traditional model of understanding risk and insuring against loss.

The ecosystem is data-driven and will require all members of the sector to undergo digital transformation. This may bring associated organisational, technical and cultural challenges (see section 5 for further discussion).

\subsection{Circular Economy Principles}

The aim of the CE is to preserve value of natural capital. CE can be considered as a form of butterfly [13] representing a two-sided circular model. Circular flows from use to re-use represent one wing of the butterfly, relating to renewable resources (e.g., energy, food, and biological materials) and a second wing relating to non-renewables or finite material (e.g., machines, cars and goods). The two sides are linked by the butterfly body representing a supply chain/transformation process of parts manufacture, completed goods manufacture, and the service provider. "End customers" can either be consumers (of renewable goods) or users of finite material goods. Key steps of re-use are exampled as maintain, prolong, share/re-use distribute/refurbish/remanufacture and recycle. An associated aim is reduced volatility and security of supply, and improved customer interaction. A principal theme is the move from patterns of behaviour based on a consumption logic to those based on a value in use 
/ co-creation and retention of value logic. The new and circular role of finance in the butterfly is not made explicit.

The embedding of $\mathrm{CE}$ principles within the ecosystem (i.e., designing waste out of the system, keeping products and materials in use, and regenerating natural systems [3]), will require a customer-centric, data-driven approach, where:

- all parties within the ecosystem embraces digital transformation,

- insurance companies within the ecosystem move to a customer-centric, servitisation business model,

- organisations have the ability to access real-time data streams required by the predictive analytics tools,

- predictive analytics is adopted that aims to encourage preventative behaviour and prevent risk,

- organisations have the ability to continuously innovate their business model.

\subsection{Customer-centric Servitisation}

Raddats et al [14] offer a definition of servitisation as "the transformation of a firm from taking a product [centric approach] - to taking a service-centric approach"(i, p207). Baines et al [15] describe three themes of servitistion, which could be considered as levels forming a servitisation journey: "Base" (post sales service); "Intermediate (ongoing maintenance); and "Advanced Services" ("customer support agreements", ongoing close relationships and "outcome [based] contracts"). Full servitisation involves radical changes to the organisation's business model matching service-based costs with service-based revenues. Servitisation experience and literature tends to be focussed on B2B scenarios, where the immediate customer of the servitising firm is not the end user. As servitisation extends its influence, this is not likely to continue, especially when it begins to impact on "services" such as insurance.

To embed the CE principles of designing waste out of the system and keeping products and materials in use, Circular Insurance will require insurance companies to both insure the use of the asset (and not the asset itself), and to price the insurance based on reusable elements in the asset. The ability to insure on reuse potential, not purchase price, should also be considered. A servitisation business model could facilitate this and encourage long-term use through improving focus on aligned customer and environmental outcomes.

In many sectors customers are increasingly found to be the ones that are driving innovation and, therefore, the digital transformation of an organisation. This has led to many B-to-C companies within the insurance sector considering customers a disruptive force. Customer-centric approaches ensure a positive customer experience throughout their interactions with a company. It has been considered key in ensuring customer retention and a way of providing competitive advantage. As noted by Thawadi et al. [16], some definitions of digitalisation have included the concept of customer centricity. Interestingly, it is two industry reports that are referenced namely one by McKinsey [17] and one by Bain \& Company [18]; this could indicate a divide in thinking between practitioners and academia. The report published by Bain \& Company note that customer feedback would regularly be collected and analysed to improve the customer experience by a 'truly customer centric company'; such companies would 'put customers' priorities front and center when designing products and services' [18]. The McKinsey report [17] notes that digital allows a company to gain a better understanding of their customer through analysing their interactions to provide a new 'level of customer-centricity'.

We believe a customer-centric approach to servitisation in the digital-era could, and should, go a step further. If something is customer-centric, tailoring and bespoke services should be possible. For an insurance company to thrive, it has been noted that they should be able to offer services and products that are tailored to the customer ensuring that they are relevant at the time that they need them [5]. From the perspective of a servitisation business model, this requires identifying the outcomes that are desired by a customer and continuously adapting those offerings based on their requirements. By adopting a customer-centric servitisation model, we believe the insurance sector will help to ensure relevancy, which can help encourage behaviours that embrace and enhance $\mathrm{CE}$ principles of reducing waste and keeping materials in use. Fully customised servitisation offerings challenge the current model of risk calculation in the insurance sector (e.g., from a model of risk understanding and evaluation, to a model based on customer outcomes and preventions). However, we believe it is a necessary change when moving to a model of risk prevention. 


\subsection{Access to real-time data streams}

The ability to offer a form of customer-centric servitisation business model, relies on also adopting a data-driven approach. An insurance company's ability to access relevant datasets in a timely manner is fundamental.

We have seen an increase in the use of digital technology that allows an organisation to capture data on their customers. The technology could be IoT devices (such as those that are used to monitor for a flooding event in a home or a natural disaster), usage data (e.g., car insurance companies have been installing blackboxes within customer cars that captures telematics data relating to driving behaviour [19]) or from transactional data (e.g., types and times of of interactions with the company).

In Circular Insurance, data could be considered to come from three main sources: the customer, the organisation or external. External data, may or may not be open-source (i.e., freely available) but will not be owned by the company who wishes to use it. Such datasets could provide context and help identify risk prevention strategies for a particular risk-related desired outcome. It might be weather data (e.g., if outcomes relate to protecting property from weather events) or medication data (e.g., if outcome is related to health of a pet). Organisational data might relate to interactions between an organisation and customer, popular desired outcomes, or help to quantify risk profiles to aid in risk prevention strategies.

Customers may generate personal or non-personal data. Any information, or collection of information, that relates to an identified or identifiable living individual is considered personal data [20]. Anonymised data is not considered personal data. However, if such data can be combined with other datasets to identify the individual in question, it will be considered personal data. The telematics data collected in a vehicle's black box could constitute such data. Insurance companies already make use of a customer's personal data (e.g., address, DOB, bank details). Some of this data may be used to assess the risk that they need to insure against (e.g., area where they live, age, criminal convictions and health conditions).

When considering access rights to datasets within the Circular Insurance ecosystem, we must consider the question of data ownership and mechanisms that would facilitate data sharing. The ability to securely and efficiently share data aligns with the CE principles of reducing waste. Life and health insurance companies already exchange discounts on policies for those customers that share their personal fitness data. We believe that the need to share data, including personal data, will only increase. It has been noted that it is possible that part of the value chain in the near future could be lost to other industries [21]. This could allow companies to outsource tasks to specialised companies (e.g., that have predictive analytics capabilities) or to gain access to the data. Although the insurance company may provide IoT devices, they may not have access to all of the data that is required. The model may require partnerships with companies in other industries.

For Circular Insurance to work, we suggest the need for an inbuilt data sharing mechanism within the ecosystem that would allow all parties involved to benefit from sharing data, including the use of personal data, whilst protecting the rights of the individual who the data involves. Section 4 discusses possible data sharing mechanisms.

The use of data sharing in the ecosystem does raise questions around monetisation of personal data and the data sharing economy [22] (see section 5).

\subsection{Adopting predictive analytics}

The analysis of datasets can provide insights into new value propositions. The use of IoT devices, and data analytics, currently allows the creation of smaller risk pools [21]. In parametric insurance data analytics can be used to replace loss adjustors and claims processes to identify when a payout is needed and how much it is for (e.g., by establishing the extent of flood damage using sensor data). Within Circular Insurance we suggest going a step further by utilising predictive analytics to help move towards a model which aims to prevent risk by advising customers on how to prevent risk, and or the likelihood of an event occurring (e.g., flooding event likely soon). If the concept of Circular Insurance is applied to parametric insurance, predictive analytics would be used to try to avoid the event that would trigger the claim.

The move to risk prevention, instead of the traditional approach of understanding of risk, helps ensure alignment with the CE principles. The avoidance of an event that would usually trigger a claim helps to design waste out of the system and keep products and materials in use. The Circular Insurance model would encourage preventive behaviour, which would also help adhere to these principles.

We live in a very dynamic environment. This means the capture and analysis of data in near real-time. This can pose both technical and ethical challenges. The predictive analytics would need to continuously evaluate different solutions and make recommendations to the customer (if it is something that cannot be handled 
automatically such as closing the window in a smart home when heavy rain is forecast or shutting hurricane shutters when a storm is due in a home that is currently empty). Advances in digital technologies (e.g., AI and High Performance Computing) can handle datasets of considerable sizes. However, research is still needed to improve the efficiency and cost (in both time and energy) of running them. It is possible that areas of research such as Edge Computing (EC) [23] and the associated Machine Learning (ML) methods designed for the EC paradigm such as federated learning (e.g., [24]) or transfer learning (e.g., [25]) could help.

Data analytic platform providers offer solutions that require low code and minimal data science skills. This can be advantageous to organisations who do not wish to outsource the data analysis or hire data scientists. However, it can be problematic for organisations whose analytics is resulting in decisions that will impact the customer. It is important that the way in which the decision has been made is transparent and explainable. Transparency and explainability of Artificial Intelligence (AI) algorithms are two active areas of research.

\subsection{Continuous innovation of business models}

Our research has shown us that we need to move through innovative product offerings (e.g., parametric insurance), to more holistic and customer-focused offerings which will involve constantly innovating the business model. This move is possible due to datafication, advances in digital technologies and servitisation. Constantly innovating the business model would allow organisations to evolve and provide agility to keep pace with changing customer needs and further advances in technology.

\section{Possible Solution}

Figure 1 depicts a possible solution for how the Circular Insurance might work. It is important to note that it is only one conceptualisation and identifying the best solution forms part of the ongoing research.

The aim of the ecosystem is to use innovative digital technologies to encourage and reward behaviours that embrace and enhance CE principles and, therefore, facilitate a customer-centric, data-driven, outcome-based approach. The proposed solution facilitates a servitisation model that focuses on risk prevention.

Within the ecosystem there will be a set of actors. At this stage, actors can be classified as either customers or organisations. To illustrate the key concepts figure 1 only depicts three actors within the ecosystem: one

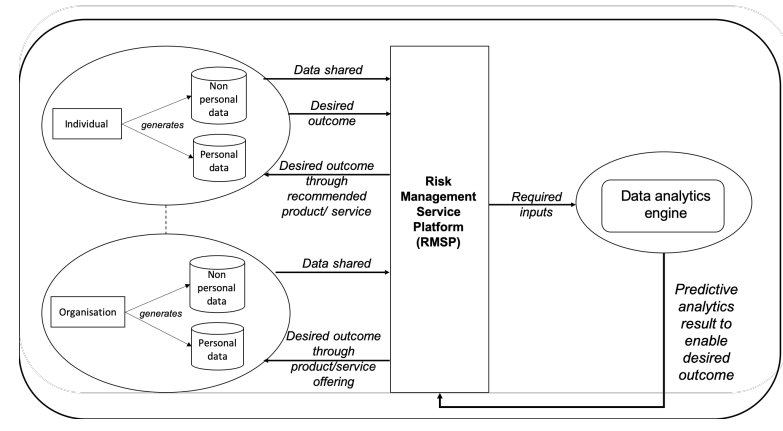

Figure 1. The Circular Insurance Approach

customer and two organisations (one of which provides the data analytics capabilities and could be a specialist data analytics company). In reality there would be many.

The ecosystem embraces digital transformation through the use of innovative digital technologies to continuously collect, interpret and leverage data. The arrows within figure 1 reflect data flow and continuous feedback via the Risk Management Service Platform (RMSP). Each actor generates their own data, which may be through some form of IoT device (e.g., sensor, or telematics) or via transactions. In the ecosystem access to data could be needed by more than those that own it. We propose each actor have their own form of Personal Data Store (PDS). A PDS can be considered a vault which is owned by an individual and contains their own personal data. The individual can choose who and what data they wish to share with others or restrict access [26]. Example PDSs for individuals include the Hub of all Things (HAT) [27], Mydex [28] and Digi.me [29].

The proposed solution allows organisations to also have their own form of data store. We are exploring this possibility to reflect the evolution of the future value chain, and the possible loss to other industries [21]. It is envisioned that providing an organisation with their own variant of a personal data store will help facilitate data-sharing on a wider scale allowing the emergence of new digital (i.e., data-driven) business models. Based on the principles of Circular Economy we believe that insurance data should be managed and shared by a data platform. This is particularly important in insurance where transactions occur B-B, not just B-C, and an insurance company is often not dealing directly with the customer but through an intermediary. Determining the value of data and establishing the associated economic models are out of the scope of this paper but will need to form part of ongoing research in the further development of Circular Insurance.

Data sharing and data privacy are considered as 'potential obstacles for insurers' [9]. The RMSP, connected the different PDSs, facilitates secure and 
privacy-preserving real-time data sharing between the different actors (i.e., individual to organisation or organisation to organisation). Each actor can choose what data to share and with whom but it must go via a RMSP. In figure 1, the platform is controlled by a third party (to facilitate B-B and B-C). However, it is possible that an organisation might have its own RMSP. If this is the case, the data sharing and service provision will occur directly between an organisation and individual (represented by the dotted line in figure 1).

We recognise that each organisation may have some data analytics capabilities. However, for the real-time data collection and analysis, a technological solution may need to be developed where actors act as 'edge' nodes with some of the data analytics taking place at the edge. This would mean only a subset of data needs to be passed to the data analytics engine where the predictive analytics take place. Within figure 1 the data analytics engine is represented as a third actor. This reflects the specialist nature of the task and the possibility of outsourcing to another company within, or outside, the insurance sector.

The aim of the data analytics engine is to identify and output the recommendations that would allow customer-desired outcomes which will also be predicated on CE principles; in insurance this would be primarily to prevent risk but additional customer-desired outcomes could be specified by an individual through their PDS. The recommendations made to a customer, via the RMSP and PDSs to preserve privacy, could result in a behaviour change due to a specific action (e.g., improve insulation of a home) or additional products/services that they should consider from one of the organisations in the eco-system. This is possible since the organisations within the ecosystem can also share data regarding their offerings via their own form of PDS. A change in behaviour would be captured by the ongoing data capture and the ecosystem updating accordingly. To aid in transparency we would recommend that probabilities are attached to all recommendations to aid the actor in their decision making. Recommendations can also be fed back to the organisation, which could relate to suggested changes in product/service offerings (i.e., suggestions that would allow continuous innovation of business model) or help them cost insurance on asset usage. To help reduce waste, the data analytics engine could use the data to influence design for $\mathrm{CE}$ and help advice on how to insure an asset based on reuse potential.

\section{Challenges and possible barriers to adoption}

This conceptual paper has presented a possible future model for the insurance sector that is driven by innovative digital technologies and the development of a data-sharing economy. The adoption of a Circular Insurance within insurance fulfils the trends that those in the sector believe must occur in order for insurance companies to thrive in the Digital Economy. However, there are barriers, challenges and implications that will need to be considered to allow wide-scale adoption.

\section{Ethical and legal considerations:}

Circular Insurance relies on real-time data collection and analysis, and the ability to share data, where what, and to whom it is shared, is the responsibility of the owner of the data. Although there are current regulations relating to personal data, further regulation will need to be developed, particularly with regards to regulating the value of data and data ownership. Much of the data collection will rely on technologies that are owned by third parties.

The risk management framework, and use of Personal Data Stores, have been suggested to help ensure control, and access rights, over data. The use of Edge Computing may help reduce the amount of data that has to be shared to help in preserving privacy of individuals. The success of the predictive analytics will depend on the quality of the datasets. Any legal and ethical regulations should specify how to ensure the quality and reliability of the data that is being handled.

As previously noted, when analytics results in decisions that will impact the customer it is important that the way in which the decision has been made is transparent and explainable. Transparency and explainability of Artificial Intelligence (AI) algorithms are two active areas of research.

The use of digital tracking and predictive analytics may bring unintended negative consequences. The proposed model aims to prevent risk and encourage change in behaviour. Although this could be considered by a customer a desired outcome and help facilitate CE principles, it may have unintended negative effects on themselves or on others. Some individuals may not be able to change certain behaviours (e.g., due to a genetic disease [21]). The ethical and wider societal implications of changing individuals behaviour must be carefully considered [21]. 
Technical challenges:

Real-time data and predictive analytics brings technical challenges. The recent pandemic has highlighted that abnormal events can lead to existing data analytic methods struggling. The amount and complexity of the datasets bring challenges for algorithm development and ensuring reliable infrastructures. Edge Computing has been suggested as a possible solution but further research is needed to explore other options.

Protocols will also need to be developed to facilitate data sharing and ensure that data is only collected, and stored, when needed. It is very easy to keep collecting data resulting in a data deluge for an organisation. It should be possible to ensure data collection is efficient but only done when necessary (e.g., when a change occurs).

\section{Cultural challenges and skills pipeline:}

The operating models of insurance companies will need to adapt as they go through digital transformation. It is likely that these operating models will require skills that are currently not prominent in the insurance sector. The proposed ecosystem does recognise the possibility of outsourcing and loss in the value chain to other industries. However, re-skilling of the workforce should also be a key part of digital transformation projects. Digitalisation and datafication will also have implications for the roles and skills required by an organisations. Organisations will need to work with their employees to undertake regular skills audits and establish what the future skills pipeline may look like. This will help in the development of re-skilling programmes.

The move towards a system that prevents risk, instead of understanding risk, will require a substantial culture change in the sector. Training and education programmes will need to be developed that can allow an organisation to move as one.

\section{Future Research Areas}

As part of ongoing research, discussions with representatives from the insurance sector whilst developing the concept of Circular Insurance has identified areas where further research is needed. This research should be carried out in partnership with industry to accelerate the knowledge transfer and could form the beginnings of a research agenda.
Consideration of $B-$ to- $B$ :

B-to-B companies within the insurance sector often find it difficult to identify the end user. This makes it difficult to adopt a customer-centric approach. Further research is needed to understand the supply and value chain in the B-to-B insurance sector and establish if a customer-centric model is possible, and if it is, what it may look like.

\section{Identification of new markets:}

The move towards a model that prevents risks instead of understanding risk is likely to lead to the creation of new markets. It has been noted that data-driven approaches, that require large amounts of data to be stored and processed, increases an organisations cyber-risk. $51 \%$ of the respondents in the Deloitte survey believed that cyber and data regulations would be the top challenge when trying to adjust to digital disruption. The field of cyber-insurance will continue to grow. It is feasible to see a market within the insurance sector that is related to the processing and management of personal data. Further research is needed to help identify potential new markets and how these can be encouraged.

\section{Future of work:}

Circular Insurance would assist organisations in evolving their operating models and continuously innovate their business models. Changing their services will help them become embed CE principles. Digitalisation and datafication will also have implications for the roles and skills required by an organisations. Automation could lead to the existing roles becoming redundant and the need for employers to move to other value-add roles. Further research is needed to understand the implications for the future of work and how academics can work with industry partners to develop suitable training programmes to provide a skills pipeline for the insurance sector.

\section{Value of data and data sharing models:}

Data-driven models allow data to be monetised. Ongoing research is exploring the value of data, suitable data ownership models and the associated economic models. Protocols will also need to be developed to ensure secure and privacy-preserving data sharing. 
New analytical tools:

Real-time data and predictive analytics brings technical challenges. The recent pandemic has highlighted that abnormal events can lead to existing data analytic methods struggling. The amount and complexity of the datasets bring challenges for algorithm development and infrastructure providers. Transparency and explainability will play important roles in facilitating predictive analytics.

\section{Education:}

Digital transformation and the move towards servitisation can lead to concerns within and external to an organisation. Education programmes can help to ease the transition, explain aims, manage expectations and develop suitable re-skilling programmes.

\section{Conclusions}

There is a push for all sectors to play their role in moving to a more sustainable system by embedding Circular Economy principles into their organisations. Based on our ongoing research in servitisation, CE and the insurance sector, this conceptual paper has presented the concept of Circular Insurance, a new finance insurance ecosystem that uses innovative digital technologies to encourage and reward behaviours that embrace and enhance CE principles. The move from an analogue world to a digital one (i.e., digitisation), has led to the 'age of immediacy' and new demands. The proposed approach is a customer-centric, data-driven approach to insurance. The adoption of Circular Insurance within insurance fulfils the trends that those in the sector believe must occur in order for insurance companies to thrive in the Digital Economy. The possible barriers in adopting Circular Insurance relating to ethical and legal considerations, technical challenges, cultural challenges and the skills pipeline has been considered. Areas of further research have been identified, which could form the beginnings of a research agenda for Circular Insurance. The research will require an interdisciplinary approach bringing together academics and practitioners in Business, Computer Science and Change Management.

\section{Acknowledgment}

The authors are grateful for the support of the Engineering and Physical Science Research Council through the Digitally Enhanced Advanced Services NetworkPlus funded by grant ref EP/R044937/1 of which this research is part of.

\section{References}

[1] G. Vial, "Understanding digital transformation: A review and a research agenda.," The Journal of Strategic Information Systems, vol. 28, no. 2, pp. 118-144, 2019.

[2] S. R. K. Brandt, "Circular economy at work in google data centers. case study," Google \& The Ellen Macarthur Foundation, September 2016.

[3] T. E. M. Foundation, "What is a circular economy - concept." Online. Available at: https: / / www.ellenmacarthurfoundation. org/circular-economy/concept. [Last accessed: July 2020].

[4] A. of British Insurers (ABI), "Uk insurance \& long-term savings key facts." Online. Available at: https://www.abi.org.uk/globalassets / files/publications/public/key-facts/ key_facts_2019_spread.pdf, December 2019.

[5] Deloitte, "A demanding future. the four trends that define insurance in 2020." Online. Available at: https://www2.deloitte. com/content/dam/Deloitte/uk/ Documents/financial-services/ deloitte-uk-insurance-trends-2019. pdf, 2019.

[6] M. . Company, "Digital disruption in insurance: Cutting through the noise." Online. Available at: https://www.mckinsey.com/ /media/ mckinsey/industries/financialo 20 services/our\%20insights/time\% 20 for\%20insurance 20 companies\% 20 to\%20face $\% 20$ digital\%20reality/ digital-disruption-in-insurance.ashx. [Last accessed: July 2020], March 2017.

[7] $\mathrm{PwC}$, "The future of risk. the insurance risk function of the future." Online. Available at: https://www.pwc.co.uk/ financial-services/assets/pdf/ future-of-risk-in-insurance-report. pdf, September 2019.

[8] V. Dinges, F. Urmetzer, V. Martinez, M. Zaki, and A. Neely, The future of servitization: Technologies that will make a difference. University of Cambridge, Cambridge.: Cambridge Service Alliance, 2015.

[9] H. Albrecher, A. Bommier, D. Filipović, P. Koch-Medina, S. Loisel, and H. Schmeiser, "Insurance: models, digitalization, and data science," European Actuarial Journal, vol. 9, no. 2, pp. 349-360, 2019.

[10] A. of British Insurers (ABI), "Uk insurance and long-term savings the state of the market." Online. Available at: https://www.abi.org.uk/ globalassets/files/publications/ public/data/abi_bro4467_state_of market_v10.pdf. [Last accessed: July 2020], February 2018.

[11] R. Maull, P. Godsiff, and C. Mulligan, "Driving competitiveness through servitization: The impact of interconnectivity and big data analytics," in 9th International EurOMA Service Operations Management Forum (SOMF), (Copenhagen, Denmark), January 19-20 20172017. 
[12] M. Lycett, “'datafication': making sense of (big) data in a complex world.," European Journal of Information Systems, vol. 22, no. 4, pp. 381-386, 2013.

[13] E. M. Foundation, SUN, M. C. for Business, and Environment, "What is a circular economy - infographic." Online. Available at: https: //www.ellenmacarthurfoundation.org/ circular-economy/concept/infographic, 2017.

[14] C. Raddats, C. Kowalkowski, O. Benedettini, J. Burton, and H. Gebauer, "Servitization: A contemporary thematic review of four major research streams.," Industrial Marketing Management., 2019.

[15] T. Baines, A. Ziaee Bigdeli, O. Bustinza, V. Shi, J. Baldwin, and K. Ridgway, "Servitization: revisiting the state-of-the-art and research priorities.," International Journal of Operations \& Production Management, vol. 37, no. 2, pp. 256-278, 2017.

[16] M. A. Thawadi, F. Sallabi, M. Awad, and K. Shuaib, "Disruptive iot-based healthcare insurance business model.," in 2019 IEEE International Conference on Computational Science and Engineering (CSE) and IEEE International Conference on Embedded and Ubiquitous Computing (EUC), pp. 397-403, IEEE, 2019.

[17] T. Catlin, R. Hartmann, L. Segev, and R. Tentis, "The making of a digital insurer: The path to enhanced profitability, lower costs and stronger customer loyalty,." Online. Available at: available at http://www.mckinsey.com/industries/ financial-services/our-insights/ the-making-of-a-digital-insurer. [Last accessed July 2020], McKinsey \& Company, The Making of a Digital Insurer: The Path to Enhanced Profitability, Lower Costs and Stronger Customer Loyalty 2015.

[18] F. Müller, H. Naujoks, H. Singh, G. Schwarz, A. Schwedel, and K. Thomson, "Global digital insurance benchmarking report 2015.” Online. Available at: http://www.bain.com/Images/GLOBAL-DIGITALINSURANCE-2015.pdf. [Last accessed: July 2020], Bain \& Company, 2015.

[19] V. Roel, K. Antonio, and G. Claeskens, "Unraveling the predictive power of telematics data in car insurance pricing," Available at SSRN 2872112., 2017.

[20] E. Commision, "What is personal data?" https://ec.europa.eu/info/law/ law-topic/data-protection/reform/ what-personal-data_en [Last accessed: July 2020], 2020.

[21] M. Eling and M. Lehmann, "The impact of digitalization on the insurance value chain and the insurability of risks," The Geneva papers on risk and insurance-issues and practice, vol. 43, no. 3, pp. 359-396, 2018.

[22] I. Ng, "The market for person-controlled personal data with the hub-of-all-things (hat)," Warwick Manufacturing Group, 2018.

[23] W. Shi, J. Cao, Q. Zhang, Y. Li, and L. Xu, "Edge computing: Vision and challenges," IEEE Internet of Things Journal, vol. 3, pp. 637-646, 2016.

[24] J. Konečnỳ, H. B. McMahan, F. X. Yu, P. Richtárik, A. T. Suresh, and D. Bacon, "Federated learning: Strategies for improving communication efficiency," arXiv preprint arXiv:1610.05492., 2016.
[25] S. Ruder and B. Plank, "Learning to select data for transfer learning with bayesian optimization," in Proceedings of the 2017 Conference on Empirical Methods in Natural Language Processing, (Copenhagen, Denmark.), pp. 372-382, 2016.

[26] T. Kirkham, S. Winfield, S. Ravet, and S. Kellomäki, "The personal data store approach to personal data security," IEEE security \& privacy, vol. 11, no. 5, pp. 12-19, 2012.

[27] H. of All Things (HAT), "Hub of all things (hat)."

[28] Mydex.org, "Discover the mydex platform."

[29] D. LTD, "digi.me." 